\title{
Transcriptional Profile of Escherichia coli in Response to Novispirin G10
}

Thomas Kruse · Bjarke Christensen - Dorotea Raventós · Allan K. Nielsen · Jesper D. Nielsen · Natasa Vukmirovic · Hans-Henrik Kristensen

Published online: 21 February 2009

(C) Springer Science+Business Media, LLC 2009

Erratum to: Int J Pept Res Ther DOI 10.1007/s10989-008-9157-9

Due to a production error, this article was previously published in the March 2009 issue of this journal (Vol. 15, No. 1).

The online version of the original article can be found under doi:10.1007/s10989-008-9157-9.

T. Kruse · D. Raventós · A. K. Nielsen ·

J. D. Nielsen · N. Vukmirovic $\cdot$ H.-H. Kristensen ( $\square)$

Novozymes A/S, Bagsvaerd 2880, Denmark

e-mail: hahk@novozymes.com

B. Christensen

Novozymes A/S, Davis, CA, USA 


\title{
Transcriptional Profile of Escherichia coli in Response to Novispirin G10
}

\author{
Thomas Kruse - Bjarke Christensen - Dorotea Raventós · \\ Allan K. Nielsen · Jesper D. Nielsen - Natasa Vukmirovic · \\ Hans-Henrik Kristensen
}

Accepted: 26 September 2008

(C) Springer Science+Business Media, LLC 2008

\begin{abstract}
Using a novel methodology, we have investigated the transcriptional response of Escherichia coli to novispirin G10, an $\alpha$-helical cationic antimicrobial peptide. We show that novispirin G10 induces an exceptionally coherent transcriptional response in E. coli, resulting in upregulation of genes involved in response to osmotic stress, acid shock, phage shock, and antimicrobial peptides, and down-regulation of the heat shock response genes, e.g., dnaJK, GroES, and GroEL. This transcriptional pattern indicates that novispirin G10 acts by compromising the bacterial membrane and possibly also by targeting the heat shock response. The impact of novispirin G10 on E. coli cells was monitored directly using the fluorescent LIVE/ DEAD assay verifying that the peptide, indeed, targets bacterial membranes. Furthermore, in agreement with the observed heat shock transcriptional response, we show that overexpression of the heat shock transcription factor in E. coli, $\sigma^{32}$, leads to a significant decrease in sensitivity towards novispirin G10.
\end{abstract}

Keywords Novispirin G10 - Antimicrobial peptides · Mode-of-action · Transcriptional profiling .

DNA microarray analysis

T. Kruse $\cdot$ D. Raventós $\cdot$ A. K. Nielsen .

J. D. Nielsen · N. Vukmirovic $\cdot$ H.-H. Kristensen $(\bowtie)$

Novozymes A/S, Bagsvaerd 2880, Denmark

e-mail: hahk@novozymes.com

B. Christensen

Novozymes A/S, Davis, CA, USA

\section{Introduction}

The rapid emergence of resistance to conventional antimicrobial agents is a growing problem in fighting bacterial and fungal infections. In contrast to conventional antibiotics, such as penicillin, development of resistance to antimicrobial peptides (AMP) is rare, and antimicrobial peptides therefore constitute an interesting alternative to marketed antibiotics (Coates et al. 2002; Zasloff 2002). Antimicrobial peptides are found in a variety of plants and animals, where they are part of a first line of defense against infections, making them ancient 'natural peptide antibiotics' (Ganz et al. 1985; Koczulla and Bals 2003; Nizet et al. 2001). Most antimicrobial peptides are cationic molecules, having a mode of action closely associated with their binding to negatively charged phospholipids that are exposed on the outer leaflet of bacterial membranes (Zasloff 2002). Several detailed models have been proposed to account for the rapid lysis of the target cells (Brogden 2005). However, there is mounting evidence indicating that antimicrobial peptides have multiple targets and that a subset of the peptides can traverse the bacterial membrane, exerting their bactericidal effects on intracellular targets as well as on the membrane (Brogden 2005; Hale and Hancock 2007; Hong et al. 2003; Otvos 2000; Patrzykat et al. 2002; Peschel and Sahl 2006; Wu et al. 1999; Yeaman and Yount 2003).

Here, we set out to investigate the transcriptional response and, thus, the mode of action of the AMP novispirin G10, which is a derivative of the N-terminal 18 amino acids of the sheep cathelicidin SMAP29 (Sawai et al. 2002). Novispirin G10 showed efficacy in several animal infection models against $S$. aureus and $P$. aeruginosa implicating its potential as an alternative antimicrobial therapeutic (Jacobsen et al. 2007; Song et al. 
2005; Steinstraesser et al. 2002). Transcriptional profiling is a relatively new approach used to gain insight in the biological responses to various external physico-chemical stimuli. The method has been used successfully to fingerprint comprehendible cellular responses to sub-lethal exposure to traditional antibiotics ( $\mathrm{Ng}$ et al. 2003). However, the method has been used with less success for antimicrobial peptides (AMPs) where the resulting profiles seem uncoordinated (Hong et al. 2003; Tomasinsig et al. 2004). This can be explained by several factors such as the speed of killing (within minutes) and the special feature of many AMPs where the concentration leading to inhibition (minimal inhibitory concentration-MIC) often is identical to the concentration leading to cell death (minimal bactericidal concentration-MBC).

Therefore, an alternative experimental setup where the bacterial cells were engineered to conditionally produce a periplasmic space targeted novispirin G10, thereby creating a local level of exposure to the AMP was employed. The rationale behind this approach is that as the AMP starts to build up and compromise the cellular integrity, the membrane potential and hence energy source for further AMP synthesis decreases. This results in a pseudo-steady state where the AMP-induced damage never reaches a level high enough to actually kill the cell. Through fine-tuning of the AMP synthesis, a controlled environment of maximum AMP-induced, sub-lethal stress is induced-the ideal background for studying the transcriptional response to the AMP. As a consequence of this novel strategy, the transcriptional response was exceptionally coherent and biologically relevant as shown directly by additional biochemical and genetic approaches.

\section{Materials and Methods}

Peptides

Peptides were produced by solid phase synthesis (K. J. Ross-Petersen, Denmark, www.ross.dk) and the corresponding sequences were novispirin G10: KNLRRIIRKG IHIIKKYG; IB-367: RGGLCYCRGRFCVCVGR-amide.

\section{Plasmid Construction}

Inducible novispirin G10 vector. A plasmid vector, pDRS5-novispirin G10 containing the novispirin G10 gene was constructed by annealing the DNA primers DR8F (5'-ccggccatggcgAAAAACCTGCGTCGCATTATCCGC AAAGGCATCCATATCATTAAAAAATATGGCtagatgg ctctagacggc- $3^{\prime}$ ) and DRO (5'-GCCGTCTAGAGCCATC TA- $3^{\prime}$ ) and filling out the DNA duplex using Taq Pwo polymerase (Roche). The resulting product was digested with $N c o I / X b a I$ and ligated into the pBAD vector gIII A (Invitrogen). The construct was confirmed by sequence analyses and was transformed into E. coli TOP10 cells (Invitrogen).

\section{Inducible RpoH-Vector}

The rpoH-gene was PCR amplified from E. coli TOP10 using the DNA primers rpoH-forw1 (5'-taacaggagga attaaccatgatgactgacaaaatgcaaagtttagcttt- $3^{\prime}$ ) and rpoH-rev $\left(5^{\prime}\right.$-tttgttctagattacgcttcaatggcagcgcgcaatttttcatcgcg- $\left.3^{\prime}\right)$. A DNA fragment of approximately $880 \mathrm{bp}$ was purified and used as template in another PCR reaction using the DNA primers rpoH-forw2 (3'-tagcggatcctacetgacgettttatcgcaact ctctactgtttctccataccegttttttgggctaacaggaggaattaaccatgatgact gac-5 $5^{\prime}$ ) and rpoH-rev. The amplified fragment was purified and restricted with $N c o \mathrm{I}$ and $\mathrm{Xba \textrm {I }}$ and cloned into the plasmid pBAD gIII A. The correct sequence was verified by DNA sequencing.

\section{Preparation of Bacterial Cultures for Microarray Analyses}

E. coli TOP10 cells (Invitrogen) transformed either with the novispirin G10 expressing construct (pDRS5-novispirin G10) or the control vector were grown to exponential phase in RM media (see Invitrogen catalog no. V450-01) supplemented with $100 \mathrm{mg} / \mathrm{l}$ ampicillin and $0.1 \%$ arabinose (Ferro-Pfanstiehl A-121) and subsequently transferred to centrifugation tubes containing $10 \mathrm{ml}$ pre-frozen milliQ water. Cells were immediately harvested by centrifugation at $4,200 \times g$ for $15 \mathrm{~min}$ at $4^{\circ} \mathrm{C}$. The supernatant was decanted and the pelleted cells were frozen at $-80^{\circ} \mathrm{C}$ until RNA extraction was performed.

\section{RNA Isolation and Labelling}

Total RNA was isolated from the two E. coli cultures (expressing either novispirin G10 or a control peptide) by use of the High Pure RNA Isolation kit (Roche, cat \#1828665) according to the manufacturer's instructions. Residual DNA was removed on-column with RNase-free DNase. Labelled samples were prepared from $30 \mu \mathrm{g}$ of total bacterial RNA. Fluorescent first strand cDNA was prepared by random primed reverse transcription (Superscript II; Life Technologies) by use of random hexamers for cDNA synthesis. A total of $2 \mu \mathrm{l}(20 \mu \mathrm{g})$ of random primer was mixed with $15 \mu \mathrm{l}(30 \mu \mathrm{g})$ of total RNA, incubated for $5 \mathrm{~min}$ at $70^{\circ} \mathrm{C}$, and cooled on ice. To each sample was added $5 \times$ first strand buffer $(6 \mu \mathrm{l}), 0.1 \mathrm{M}$ DTT $(3 \mu \mathrm{l})$, dNTP mix $(5 \mathrm{mM}$ dATP, dGTP and dTTP and $2 \mathrm{mM}$ dCTP) $(1 \mu \mathrm{l})$, RNaseOut $(1 \mu \mathrm{l})$, Superscript II reverse transcriptase $(2 \mu \mathrm{l})$ and Cy-dCTP $(3 \mu \mathrm{l})$. Reverse 
transcription was carried out at $42^{\circ} \mathrm{C}$ for $1 \mathrm{~h}$. RNA was removed by addition of $10 \mu \mathrm{l} \mathrm{NaOH}(1 \mathrm{M})$ and incubation at $65^{\circ} \mathrm{C}$ for $10 \mathrm{~min}$. The samples were neutralised by addition of $10 \mu \mathrm{HCl}(1 \mathrm{M})$. Cy3 and Cy5 cDNA samples were mixed and immediately purified with a GFX PCR DNA and Gel Band Purification Kit (Amersham Biosciences).

\section{Hybridizations, Scanning and Analysis}

Slides were pre-hybridised at $42^{\circ} \mathrm{C}$ for $45 \mathrm{~min}$ in a solution containing $4 \times \mathrm{SSC}+0.5 \% \mathrm{SDS}+1 \% \mathrm{BSA}$ and dried by centrifugation. Hybridizations were in a volume of $25 \mu \mathrm{l}$ under a supported cover slip at $42^{\circ} \mathrm{C}$ for $16-18 \mathrm{~h}$ at high humidity. The hybridisation mixture was labelled cDNA in a formamide-based hybridisation buffer (MWGsupplied with the pan-arrays). Cover slip and supports were gently removed $(2 \times$ SSC in a wash tray) and arrays were washed by immersion into $2 \times$ SSC $+0.1 \%$ SDS for $5 \mathrm{~min}, 1 \times \mathrm{SSC}+0.1 \% \mathrm{SDS}$ for $5 \mathrm{~min}, 0.5 \times \mathrm{SSC}$ for $5 \mathrm{~min}$ and $1 \times$ millipore water for $10 \mathrm{~s}$ and dried by centrifugation. Slides were scanned on a GMS 418 scanner to detect $\mathrm{Cy} 3$ and $\mathrm{Cy} 5$ fluorescence. Data analysis was carried out using ImaGene 5.0 and GeneSight 3.5 from BioDiscovery (www.biodiscovery.com). Two biological replicate experiments with four replicate hybridisations in each experiment were carried out for generation of data.

Pan E. coli K12 Arrays from MWG Biotech were used in this study (lot No.:020206). The 4239 E. coli K12 specific oligonucleotide probes present on this glassbased DNA chip represent the complete E. coli (K12) genome

BacLight Live/Dead Membrane Permeabilization Assay

E. coli MG1655 cells were grown for at least six mass doublings in Mueller-Hinton Broth (MHB) at $37^{\circ} \mathrm{C}$ until an $\mathrm{OD}_{600}$ of approximately 0.5 . Aliquots of $200 \mu \mathrm{l}$ of cells were transferred to a V96 microwell plate (NUNC) and supplemented with a mixture of SYTO 9 and propidium iodide from the BacLight Bacterial Viability Kit L7007 as described by the manufacturer (Molecular probes). Green fluorescence was measured for 5 min using FLUOstar OPTIMA equipment (BMG LABTECH) with an excitation and emission wavelength of 485 and $510 \mathrm{~nm}$, respectively. Subsequently, various antibacterial compounds were added to the individual wells as indicated at concentrations of 2$4 \times$ the MIC. Green fluorescence readings were recorded over the next $55 \mathrm{~min}$ at $30 \mathrm{~s}$ intervals.

\section{Radial Diffusion Assay}

The assay used in this study was based on the protocols described previously (Lehrer et al. 1991) with several modifications. E. coli TOP10 (Invitrogen) cultures containing either the control vector or the sigma-32 overexpressing construct were grown overnight at $37^{\circ} \mathrm{C}$ in RM media supplemented with $100 \mathrm{mg} / \mathrm{l}$ ampicillin. Next day, duplicates of each culture were grown to exponential phase in the absence or in the presence of $0.1 \%$ arabinose. Subsequently, $3 \times 10^{6} \mathrm{CFU}$ from each culture were spread on the surface of a thin layer of a $1 \%$ agarose gel (SIGMA A-6013) containing Mueller-Hinton broth (MHB, Becton Dickinson 212322). A regularly spaced array of wells was made in the MHB agarose gel. Next, $10 \mu \mathrm{l}$ of six serially twofold diluted samples of each peptide ranging in concentration from 200 to $6.25 \mu \mathrm{g} / \mathrm{ml}$ in $0.01 \%$ acetic acid and $0.1 \%$ bovine serum albumin (Roche 775860 ) were added to the wells. The plates were incubated overnight at $37^{\circ} \mathrm{C}$ to allow bacterial growth. Finally, the resulting clearing zones were measured by a circle array program. Triplicates of each sample were run in the assay. The experiment was performed four independent times for novispirin G10 and twice for IB-367.

\section{Results and Discussion}

Based on a confidence level of $90 \%$, microarray analysis showed that 153 genes were upregulated and 92 genes were downregulated relative to a control strain that expressed a peptide without antimicrobial activity. The majority of the annotated, upregulated genes could be ascribed to a small number of physiological responses (Table 1), comprising responses to membrane dysfunction-i.e., upregulation of genes involved in acid shock, osmotic shock and the respiratory system - and functional groups related to phage shock, AMP resistance, the magnesium stimulon, nitrogen assimilation, and the carbon metabolism.

In line with the expectation of a membrane destabilizing action of an antimicrobial peptide, the transcriptional response elicited by novispirin G10 shows clear signs of compromised membrane characteristics, as indicated by upregulation of genes involved in osmotic shock response, acid resistance and the electron transport system (Yeaman and Yount 2003), (Table 1). The upregulated genes responsible for counteracting the osmotic shock include a proline/betaine transporter, proW, a putative osmoprotectant system, yehZYXW (Checroun and Gutierrez 2004), and the trehalose biosynthetic enzymes, encoded by the ots $A B$ operon. At high osmolality, betaine and proline act as osmoprotectants when available in the medium, and if not available, the intracellular level of the neutral solute, 
Table 1 Up- and down-regulated genes in response to novispirin G10

\begin{tabular}{|c|c|c|c|c|c|}
\hline Gene & b-number & Description & Functional group & Fold & $\begin{array}{l}\text { Confidence } \\
\text { level }(\%)\end{array}$ \\
\hline$d k s A$ & b0145 & dnaK suppressor protein & Acid shock & 4.1 & 95 \\
\hline$y b a S$ & b0485 & Putative glutaminase & Acid shock & 8.8 & 99 \\
\hline$n m p C$ & b0553 & Outer membrane protein, negatively regulated during growth at low $\mathrm{pH}$ & Acid shock & -6.6 & 99 \\
\hline$d p s$ & b0812 & DNA binding protein; global regulator, starvation conditions & Acid shock & 4.4 & 95 \\
\hline$y c a C$ & b0897 & orf, hypothetical protein & Acid shock & 7.4 & 99 \\
\hline $\operatorname{gadC}$ & b1492 & Putative glutamate:GABA antiporter (xasA) & Acid shock & 24.9 & 99 \\
\hline asr & b1597 & Periplasmic acid shock protein & Acid shock & 19.2 & 99 \\
\hline$y d i Z$ & b1724 & ORF, hypothetical protein & Acid shock & 9.1 & 99 \\
\hline yeaQ & b1795 & Putative transglycosylase-associated membrane protein, acid inducible & Acid shock & 6.9 & 99 \\
\hline yebV & b1836 & ORF, hypothetical protein & Acid shock & 6.9 & 99 \\
\hline$g a b T$ & b2662 & GABA aminotransferase & Acid shock & 6.5 & 99 \\
\hline$g a b P$ & b2663 & GABA permease & Acid shock & 8.2 & 99 \\
\hline $\operatorname{slp}$ & b3506 & Outer membrane protein induced after carbon starvation & Acid shock & 3.6 & 90 \\
\hline yhif & b3507 & ORF, hypothetical protein & Acid shock & 2.9 & 80 \\
\hline hdeB & b3509 & Periplasmic protein involved in acid resistance & Acid shock & 7.9 & 99 \\
\hline hdeA & b3510 & Periplasmic protein involved in acid resistance & Acid shock & 7.7 & 99 \\
\hline$h d e D$ & b3511 & Integral membrane protein, unknown function, acid inducible & Acid shock & 4.3 & 95 \\
\hline $\operatorname{gad} E$ & b3512 & Activates glutamate-dependent acid resistance $(y h i E)$ & Acid shock & 3.9 & 90 \\
\hline $\operatorname{gad} W$ & b3515 & Transcriptional regulator, AraC-type $(y h i W)$ & Acid shock & 3.0 & 80 \\
\hline yiaG & b3555 & Putative transcription factor, acid inducible & Acid shock & 10.1 & 99 \\
\hline bolA & b0435 & Morphogene, induced by osmotic shock & Osmotic shock & 13 & 99 \\
\hline dacC & b0839 & D-alanyl-D-alanine carboxypeptidase; regulated by bolA & Osmotic shock & 3.6 & 90 \\
\hline osmC & b1482 & Osmotically induced protein & Osmotic shock & 7.2 & 99 \\
\hline katE & b1732 & Catalase, hydroperoxidase HPII(III) & Osmotic shock & 9.9 & 99 \\
\hline osmE & b1739 & Osmotically inducible, activator of ntrL & Osmotic shock & 11.7 & 99 \\
\hline otsA & b1896 & Trehalose-6-phosphate synthase & Osmotic shock & 5.2 & 95 \\
\hline ots $B$ & b1897 & Trehalose-6-phosphate phosphatase & Osmotic shock & 5.6 & 99 \\
\hline yehX & b2129 & Part of putative osmoprotectant system, yehZYXW & Osmotic shock & 5.6 & 99 \\
\hline yehY & b2130 & Part of putative osmoprotectant system, yehZYXW & Osmotic shock & 4.2 & 95 \\
\hline yehZ & b2131 & Part of putative osmoprotectant system, yehZYXW & Osmotic shock & 7.1 & 99 \\
\hline proW & b2678 & High affinity transport system for glycine, betaine and proline & Osmotic shock & 7.9 & 99 \\
\hline osm $Y$ & b4376 & Hyperosmotically inducible periplasmic protein & Osmotic shock & 6.4 & 99 \\
\hline appC & b0978 & Cytochrome bd terminal oxidase, subunit I & Redox & 3.5 & 90 \\
\hline$a p p B$ & b0979 & Cytochrome bd terminal oxidase, subunit II & Redox & 47.2 & 99 \\
\hline$n d h$ & b1109 & Transfer of electrons from NADH to the respiratory chain & Redox & 3.1 & 80 \\
\hline aer & b3072 & Aerotaxis sensor receptor & Redox & 14.3 & 99 \\
\hline pspA & b1304 & Phage shock protein & Phage shock & 6.7 & 99 \\
\hline$p s p B$ & b1305 & Phage shock protein & Phage shock & 6.9 & 99 \\
\hline $\operatorname{pspC}$ & b1306 & Phage shock protein & Phage shock & 15.8 & 99 \\
\hline $\operatorname{pspD}$ & b1307 & Phage shock protein & Phage shock & 13.5 & 99 \\
\hline pspE & b1308 & Phage shock protein & Phage shock & 9.4 & 99 \\
\hline dnaK & b0014 & Heat shock protein, chaperone & Heat shock & -2.8 & 80 \\
\hline$d n a J$ & b0015 & Heat shock protein, chaperone & Heat shock & -3.0 & 90 \\
\hline lon & b0439 & Heat shock protein, protease & Heat shock & -2.9 & 80 \\
\hline $\operatorname{clp} B$ & b2592 & Heat shock protein, chaperone & Heat shock & -3.6 & 95 \\
\hline $\operatorname{grp} E$ & b2614 & Heat shock protein, stimulates DnaK ATPase & Heat shock & -3.0 & 90 \\
\hline$i b p B$ & b3686 & Heat shock protein, chaperone & Heat shock & -6.5 & 99 \\
\hline
\end{tabular}


Table 1 continued

\begin{tabular}{|c|c|c|c|c|c|}
\hline Gene & b-number & Description & Functional group & Fold & $\begin{array}{l}\text { Confidence } \\
\text { level }(\%)\end{array}$ \\
\hline$h s l U$ & b3931 & Heat shock protein, protease & Heat shock & -3.2 & 90 \\
\hline$h s l V$ & b3932 & Heat shock protein & Heat shock & -3.0 & 90 \\
\hline торB & b4142 & Heat shock protein, GroES, chaperone & Heat shock & -9.1 & 99 \\
\hline mорA & b4143 & Heat shock protein, GroEL, chaperone & Heat shock & -3.6 & 95 \\
\hline$s f m C$ & b0531 & Periplasmic pilus chaperone & Protein folding & 11.4 & 99 \\
\hline $\operatorname{crcA}$ & b0622 & phoP/phoQ-dependent enzyme, lipid A modifying enzyme & AMP resistance & 11.7 & 99 \\
\hline ais & b2252 & Homolog to polymyxin resistance gene $p m r G$ in $S$. typhimurium & AMP resistance & 14.1 & 99 \\
\hline$b 2253$ & b2253 & Putative aminotransferase; modification of lipid A with aminoarabinose & AMP resistance & 8.4 & 99 \\
\hline$b 2254$ & b2254 & Putative glycosyl transferase; LPS biosynthesis ( $p m r F$ homolog) & AMP resistance & 5.5 & 99 \\
\hline$b 2256$ & b2256 & Homolog to polymyxin resistance gene in $S$. typhimurium & AMP resistance & 4.0 & 90 \\
\hline hemL & b0154 & Glutamate-1-semialdehyde aminotransferase & $\mathrm{Mg}^{2+}$-stimulon & 8.3 & 99 \\
\hline $\operatorname{nag} A$ & b0677 & $\mathrm{N}$-acetylglucosamine-6-phosphate deacetylase & $\mathrm{Mg}^{2+}$-stimulon & 3.7 & 90 \\
\hline$n a g B$ & b0678 & Glucosamine-6-phosphate deaminase & $\mathrm{Mg}^{2+}$-stimulon (?) & 8.8 & 99 \\
\hline phoQ & b1129 & Part of two-component regulatory system with $p h o P$ & $\mathrm{Mg}^{2+}$-stimulon & 3.7 & 90 \\
\hline phoP & b1130 & Sensor in two-component regulatory system with $p h o Q$ & $\mathrm{Mg}^{2+}$-stimulon & 2.8 & 80 \\
\hline$r s t B$ & b1609 & Putative sensor kinase & $\mathrm{Mg}^{2+}$-stimulon & 3.6 & 90 \\
\hline$m g r B$ & b1826 & Hypothetical protein; induced by low magnesium & $\mathrm{Mg}^{2+}$-stimulon & 4.6 & 95 \\
\hline$m g t A$ & b4242 & Magnesium transport, PhoP/PhoQ-dependent & $\mathrm{Mg}^{2+}$-stimulon & 7.5 & 99 \\
\hline $\operatorname{nar} X$ & b1222 & Nitrate/nitrate sensor, histidine protein kinase & Nitrogen assimilation & -4.0 & 95 \\
\hline narY & b1467 & Cryptic nitrate reductase 2 , beta subunit & Nitrogen assimilation & 11.0 & 99 \\
\hline narZ & b1468 & Crytic nitrate reductase 2 , alpha subunit & Nitrogen assimilation & 4.9 & 95 \\
\hline narU & b1469 & Nitrite extrusion protein 2 & Nitrogen assimilation & 15.1 & 99 \\
\hline $\operatorname{nir} B$ & b3365 & Nitrite reductase, $\mathrm{NAD}(\mathrm{P}) \mathrm{H}$, large subunit & Nitrogen assimilation & -2.9 & 80 \\
\hline nirD & b3366 & Nitrite reductase $(\mathrm{NAD}(\mathrm{P}) \mathrm{H})$ subunit & Nitrogen assimilation & -5.7 & 99 \\
\hline nirC & b3367 & Potential nitrite transporter & Nitrogen assimilation & -3.0 & 90 \\
\hline$n r f A$ & b4070 & Component of nitrite reductase complex & Nitrogen assimilation & -12.7 & 99 \\
\hline$s f s A$ & b0146 & Probable regulator for maltose metabolism & Carbon metabolism & 6.4 & 99 \\
\hline$s f c A$ & b1479 & Putative NAD-linked malic enzyme & Carbon metabolism & 5.8 & 99 \\
\hline amyA & b1927 & Cytoplasmic alpha-amylase & Carbon metabolism & 5.8 & 99 \\
\hline$b 2097$ & b2097 & Class I Fructose 1,6 bisphosphate aldolase & Carbon metabolism & 8.1 & 99 \\
\hline$g l k$ & b2388 & Glucokinase & Carbon metabolism & 3.4 & 80 \\
\hline talA & b2464 & Transaldolase A & Carbon metabolism & 11.7 & 99 \\
\hline$t k t B$ & b2465 & Transketolase 2 isoenzyme & Carbon metabolism & 26.5 & 99 \\
\hline
\end{tabular}

trehalose, is increased through biosynthesis (Yancey 2005). Along with these solute accumulating processes, osmotic stress is evidenced by the upregulation of the osmotically inducible genes of osmC, osmE and osm $Y$.

Several genes responsive to low $\mathrm{pH}$ were found among the most upregulated genes. The most upregulated acid resistance gene is $g a d C$, which is part of the most effective of three distinct acid resistance systems present in $E$. coli, the GAD-system (Castanie-Cornet et al. 1999; Tucker et al. 2002). The GAD-system is glutamate dependent, comprising a glutamate decarboxylase, encoded by gadB or $\operatorname{gad} A$, and a membrane-associated $\gamma$-aminobutyric acid (GABA): glutamate antiporter, encoded by gadC.
According to this model, accumulation of GABA-in the case of insufficient extracellular glutamate for the GABA:glutamate antiporter system - is prevented by the export of GABA by the GABA permease encoded by gabP. Alternatively, GABA may be directed towards degradation in the central metabolism by the action of GABA aminotransferase, the first of two steps converting GABA to succinate, a tricarboxylic acid cycle intermediate. In the present case, the GAD-system is accompanied by an auxiliary enzyme, encoded by ybaS that may provide glutamate from glutamine through the action of a glutaminase (Fig. 1). Comparison of the upregulated genes in Table 1 with the results from whole-genome expression 


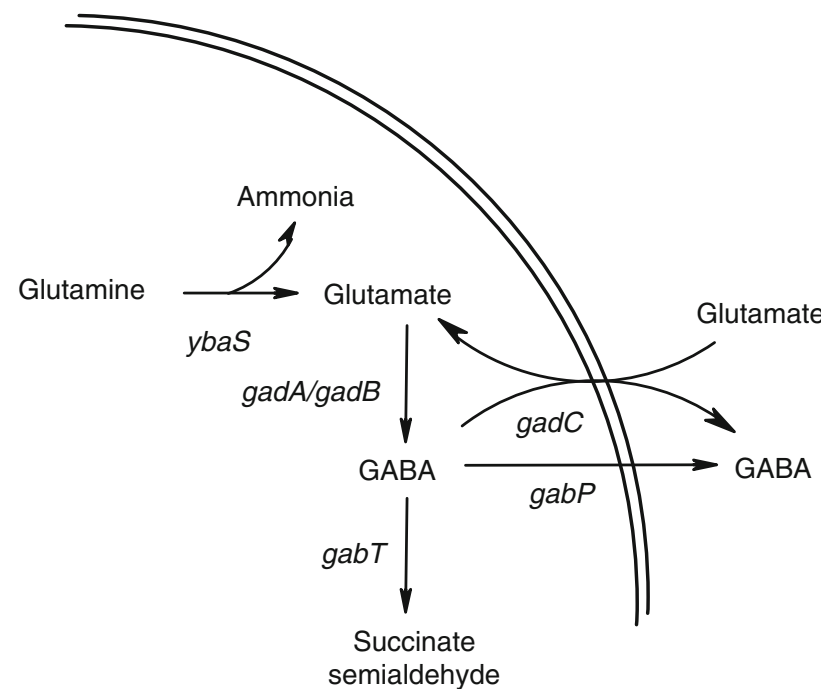

Fig. 1 Model for genes involved in acid resistance in response to novispirin G10

profiling of acid inducible genes in E. coli shows that out of 31 acid-induced genes, 18 were found to be upregulated in this study (Tucker et al. 2002).

Impaired ability to maintain gradients over the membrane also affects the redox level, explaining the 14-fold upregulation of aer, an aerotaxis sensor receptor believed to sense redox changes in the electron transport system (Taylor and Zhulin 1998). Other upregulated genes in the respiratory system are $a p p B C$, encoding a cytochrome bd terminal oxidase, and $n d h$, encoding an NADH dehydrogenase.

Since the mode of action of cationic antimicrobial peptides is dependent on their affinity for negatively charged groups on the cell membrane, lowering the electrostatic interactions between cationic antimicrobial peptides and the membrane components is a way for the bacteria to circumvent the action of antimicrobial peptides (Gunn et al. 1998; Yeaman and Yount 2003). Thus, in Salmonella spp., several genes involved in resistance to polymyxin, a cationic antimicrobial peptide, have been reported to code for enzymes that modify lipid A-a main constituent of the outer leaflet of the outer membrane-in a way that decreases the number of negative charges (Gunn et al. 1998). In this study, five genes were found to be involved in resistance to antimicrobial peptides. Four of these genes, ais (b2252), b2253, b2254 and b2256, map to a region of the E. coli genome that is homologous to the polymyxin resistance operon of S. typhimurium (Gunn et al. 1998). In addition to these genes, $c r c A$-another lipid A modifying gene regulated by PhoP-PhoQ (Bishop et al. 2000) — was found to be upregulated.

To directly examine the effect of novispirin G10 on bacterial membranes we subsequently used the LIVE/

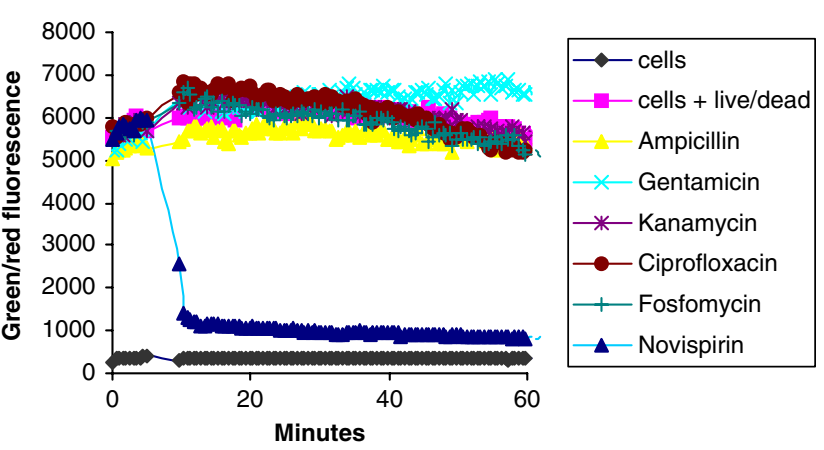

Fig. 2 Novispirin G10 permeabilizes the membranes of E. coli strain MG1655 as demonstrated using LIVE/DEAD staining. The effect of novispirin was compared with the reference antibiotics indicated. Values on Y-axis depict the green/red fluorescence ratio. All compounds were used at a concentration of $2-4 \times$ the MIC. Bacterial cells were grown and assayed in MHB medium

DEAD fluorescent assay (Materials and Methods). Briefly, the assay employs a mixture of two nucleic acid stains, the green-fluorescent SYTO 9 and the red-fluorescent propidium iodide stain. When these dyes are used together, cells with intact membranes show green fluorescence, while in cells with damaged membranes, propidium iodide enters the cells and quenches the green fluorescence. Treating E. coli cells with Novispirin G10 resulted in an immediate decrease in the green fluorescence (Fig. 2). On the other hand $E$. coli cells treated with the cell wall active antibiotics (phosphomycin and ampicillin) or compounds that target intracellular processes such as protein (gentamicin and kanamycin) or DNA (ciprofloxacin) synthesis remained intact over the entire course of the experiment. Thus, novispirin G10 clearly compromises membrane integrity of bacterial cells verifying the results obtained by the transcriptional profiling.

The phage shock genes encoded by the pspABCDE operon were all highly upregulated in response to novispirin G10. The $p s p$ operon is sigma-54 dependent and it is known to be induced by various types of stress, including hyperosmotic shock, uncoupling of the oxidative phosphorylation and nutritional downshifts (Reitzer and Schneider 2001). Stress caused by heat shock also leads to upregulation of the $p s p$-operon, an upregulation that is even further enhanced in cells with impaired ability to mount a heat shock response (Brissette et al. 1990). The finding that genes encoding central heat shock proteins, including DnaJK, GroEL, GroES, and IbpB, are downregulated (see Table 1) suggests that novispirin G10 producing cells may not elicit a normal heat shock response, thereby enhancing the upregulation of the psp-operon. Also suggestive of a reduced level of heat shock proteins, the dnaK suppressor gene, $d k s A$, was found to be upregulated. The apparent lack of a normal heat shock response may seriously affect the viability of cells growing at $37^{\circ} \mathrm{C}$, and the downregulation 


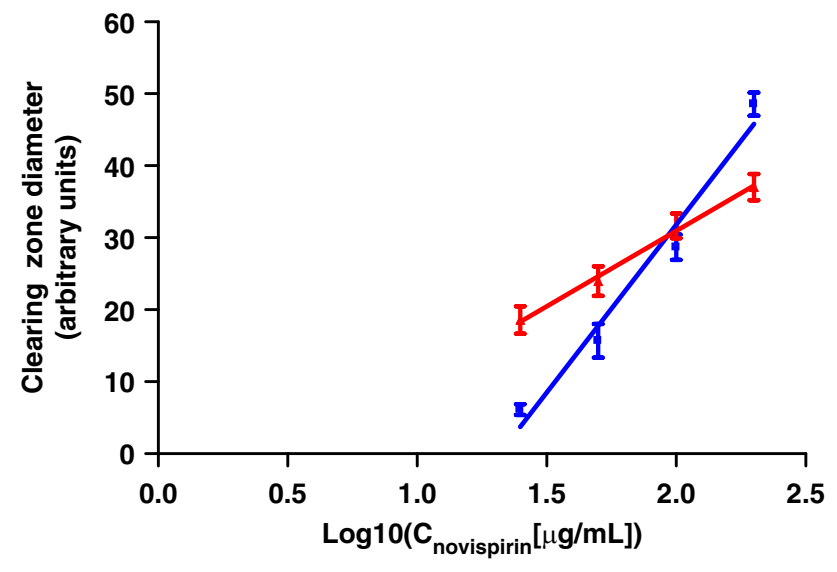

Fig. 3 Clearing zone diameter from a radial diffusion assay plotted against the logarithm to the novispirin concentration $(\mu \mathrm{g} / \mathrm{ml})$. The blue squares represent experiments in which the cells were induced by arabinose prior to the radial diffusion assay, and the red triangles represent experiments in which there was no arabinose dependent induction of $\sigma^{32}$. Extrapolation to the intercept with the $\mathrm{x}$-axis indicates the value of the (logarithm to the) minimal effective concentration (MEC)

of the heat shock genes may therefore be part of the mechanism by which novispirin G10 kills $E$. coli.

To investigate this, a strain conditionally overexpressing the heat shock transcription factor, sigma-32, was constructed. Growing the strain under inducing conditions before plating the strain onto Mueller-Hinton Broth (MHB) agarose plates, increased the minimal effectiv concentration (MEC) of novispirin in a radial diffusion assay from $3.9( \pm 2.9) \mu \mathrm{g} / \mathrm{ml}$ in the non-induced case to 20.9 $( \pm 1.8) \mu \mathrm{g} / \mathrm{ml}$ in the case of induction (Fig. 3), indicating that the upregulation of the heat shock genes makes the strain less susceptible to novispirin G10. The increased MEC supports the notion that short cationic antimicrobial peptides do not solely exert their bactericidal effect through destabilization of the membrane (Patrzykat et al. 2002). Overexpression of sigma- 32 reduced the growth rate, and to separate the effect of growth rate reduction from the effect of sigma-32 overexpression, a control experiment was performed with IB-367, an antimicrobial peptide belonging to a different class of cationic antimicrobial peptides. In this experiment, sigma-32-overexpression did not increase the MEC value, indicating that sigma-32 overexpression does not affect the resistance to antimicrobial peptides in general.

We have thus demonstrated that the transcriptional response of $E$. coli to novispirin G10 is a highly coordinated response aimed at fending off the AMP while at the same time compensating for a damaged membrane. Also the heat shock response was shown to be affected by novispirin G10, and increasing the level of the heat shock transcription factor more than doubled the minimal effective concentration (MEC) of novispirin G10. The large number of genes involved in the response to a destabilised membrane shows that the primary target of novispirin G10 is the membrane. However, the action of novispirin G10 may also be potentiated by having the heat shock response as a secondary target.

Acknowledgments We thank I. Ellingsgaard, A. L. Hansen and J. D. Larsen for expert technical assistance. Funding: The work was funded by Novozymes A/S. Transparency declarations: The authors are employees of Novozymes A/S. The authors declare that they have no other competing financial interest.

\section{References}

Bishop RE, Gibbons HS, Guina T, Trent MS, Miller SI, Raetz CR (2000) Transfer of palmitate from phospholipids to lipid A in outer membranes of gram-negative bacteria. EMBO J 19(19):5071-5080

Brissette JL, Russel M, Weiner L, Model P (1990) Phage shock protein a stress protein of Escherichia coli. Proc Natl Acad Sci USA 87(3):862-866

Brogden KA (2005) Antimicrobial peptides: pore formers or metabolic inhibitors in bacteria? Nat Rev Microbiol 3(3):238-250

Castanie-Cornet MP, Penfound TA, Smith D, Elliott JF, Foster JW (1999) Control of acid resistance in Escherichia coli. J Bacteriol 181(11):3525-3535

Checroun C, Gutierrez C (2004) Sigma(s)-dependent regulation of yehZYXW which encodes a putative osmoprotectant ABC transporter of Escherichia coli. FEMS Microbiol Lett 236(2):221-226

Coates A, Hu Y, Bax R, Page C (2002) The future challenges facing the development of new antimicrobial drugs. Nat Rev Drug Discov 1(11):895-910

Ganz T, Selsted ME, Szklarek D, Harwig SS, Daher K, Bainton DF, Lehrer RI (1985) Defensins natural peptide antibiotics of human neutrophils. J Clin Invest 76(4):1427-1435

Gunn JS, Lim KB, Krueger J, Kim K, Guo L, Hackett M, Miller SI (1998) PmrA-PmrB-regulated genes necessary for 4-aminoarabinose lipid A modification and polymyxin resistance. Mol Microbiol 27(6):1171-1182

Hale JD, Hancock RE (2007) Alternative mechanisms of action of cationic antimicrobial peptides on bacteria. Expert Rev Anti Infect Ther 5(6):951-959

Hong RW, Shchepetov M, Weiser JN, Axelsen PH (2003) Transcriptional profile of the Escherichia coli response to the antimicrobial insect peptide cecropin A. Antimicrob Agents Chemother 47(1):1-6

Jacobsen F, Mohammadi-Tabrisi A, Hirsch T, Mittler D, Mygind PH, Sonksen CP, Raventos D, Kristensen HH, Gatermann S, Lehnhardt M, Daigeler A, Steinau HU, Steinstraesser L (2007) Antimicrobial activity of the recombinant designer host defence peptide P-novispirin G10 in infected full-thickness wounds of porcine skin. J Antimicrob Chemother 59(3):493-498

Koczulla AR, Bals R (2003) Antimicrobial peptides: current status and therapeutic potential. Drugs 63(4):389-406

Lehrer RI, Rosenman M, Harwig SS, Jackson R, Eisenhauer P (1991) Ultrasensitive assays for endogenous antimicrobial polypeptides. J Immunol Methods 137(2):167-173

Ng WL, Kazmierczak KM, Robertson GT, Gilmour R, Winkler ME (2003) Transcriptional regulation and signature patterns revealed by microarray analyses of Streptococcus pneumoniae R6 
challenged with sublethal concentrations of translation inhibitors. J Bacteriol 185(1):359-370

Nizet V, Ohtake T, Lauth X, Trowbridge J, Rudisill J, Dorschner RA, Pestonjamasp V, Piraino J, Huttner K, Gallo RL (2001) Innate antimicrobial peptide protects the skin from invasive bacterial infection. Nature 414(6862):454-457

Otvos LOI Jr, I O, Rogers ME, Consolvo PJ, Condie BA, Lovas S, Bulet P, Blaszczyk-Thurin M (2000) Interaction between heat shock proteins and antimicrobial peptides. Biochemistry 39:14150-14159 $46 \mathrm{pp}$

Patrzykat A, Friedrich CL, Zhang L, Mendoza V, Hancock RE (2002) Sublethal concentrations of pleurocidin-derived antimicrobial peptides inhibit macromolecular synthesis in Escherichia coli. Antimicrob Agents Chemother 46(3):605-614

Peschel A, Sahl HG (2006) The co-evolution of host cationic antimicrobial peptides and microbial resistance. Nat Rev Microbiol 4(7):529-536

Reitzer L, Schneider BL (2001) Metabolic context and possible physiological themes of sigma(54)-dependent genes in Escherichia coli. Microbiol Mol Biol Rev 65(3):422-444 table

Sawai MV, Waring AJ, Kearney WR, McCray PB Jr, Forsyth WR, Lehrer RI, Tack BF (2002) Impact of single-residue mutations on the structure and function of ovispirin/novispirin antimicrobial peptides. Protein Eng 15(3):225-232

Song Z, Wu H, Mygind P, Raventos D, Sonksen C, Kristensen HH, Hoiby N (2005) Effects of intratracheal administration of novispirin G10 on a rat model of mucoid Pseudomonas aeruginosa lung infection. Antimicrob Agents Chemother 49(4):3868-3874

Steinstraesser L, Tack BF, Waring AJ, Hong T, Boo LM, Fan MH, Remick DI, Su GL, Lehrer RI, Wang SC (2002) Activity of novispirin G10 against Pseudomonas aeruginosa in vitro and in infected burns. Antimicrob Agents Chemother 46(4):1837-1844

Taylor BL, Zhulin IB (1998) In search of higher energy: metabolismdependent behaviour in bacteria. Mol Microbiol 28(4):683-690

Tomasinsig L, Scocchi M, Mettulio R, Zanetti M (2004) Genomewide transcriptional profiling of the Escherichia coli response to a proline-rich antimicrobial peptide. Antimicrob Agents Chemother 48(9):3260-3267

Tucker DL, Tucker N, Conway T (2002) Gene expression profiling of the $\mathrm{pH}$ response in Escherichia coli. J Bacteriol 184(23):65516558

Wu M, Maier E, Benz R, Hancock RE (1999) Mechanism of interaction of different classes of cationic antimicrobial peptides with planar bilayers and with the cytoplasmic membrane of Escherichia coli. Biochemistry 38(22):7235-7242

Yancey PH (2005) Organic osmolytes as compatible metabolic and counteracting cytoprotectants in high osmolarity and other stresses. J Exp Biol 208(15):2819-2830

Yeaman MR, Yount NY (2003) Mechanisms of antimicrobial peptide action and resistance. Pharmacol Rev 55(1):27-55

Zasloff M (2002) Antimicrobial peptides of multicellular organisms. Nature 415(6870):389-395 